Australian Journal of Educational Technology

\title{
An evaluation of the use made by students of the audio recording of lectures
}

\author{
Geoffrey Roberts \\ Queensland University of Technology
}

\begin{abstract}
The audio recording of lectures, particularly in subjects with large enrolments, offers a number of benefits to students, staff and facilities such as libraries. An evaluation of the use made by students of audio recordings of lectures revealed that students valued opportunity to listen to the lectures they had missed whilst also reducing the number of students seeking academic staff to ask questions. The ability to make copies of the audio recordings was used by students to learn away from the library which reduces pressure on library facilities. The study also revealed that few students deliberately missed lectures on a regular basis, even though they knew the lecture was being recorded. The results produced a number of insights into how students used audio materials in their learning.
\end{abstract}

\section{Background}

The audio recording of lectures at universities is a fairly common practice with some campuses recording lectures on a very regular basis while other institutions record lectures only on a special request. In 1993 a grant was obtained from the QUT Teaching and Learning Development Small Grant Scheme to carry out an evaluation of the use made by students of audio cassette recording of lectures with a view to gathering systematic data on whether this practice was of benefit to the students and how students might use this form of media in their learning. Prior to this project lectures had been recorded on an ad hoc basis at QUT, with the recordings sometimes placed in the library or distributed to external studies students. Video recordings were also being made of lectures at the Brisbane campuses for sending to the QUT campus on the Sunshine coast, a drive of about an hour north of Brisbane.

A number of issues associated with the audio recording of lectures for use by on-campus students seemed useful to investigate. Firstly with large class numbers in some first year course the audio recordings of the 
lectures was seen as a means of providing an opportunity for students who missed a lecture to catch up on the lecture material without needing to seek out a lecturer or tutor to find out what had been missed. With increasing numbers of students who have English as a second language the existence of the tapes was seen as a means of these students being readily able to revise material without the need to approach staff members. It was also felt that the tapes could be used by students to prepare for tutorials and examinations. Questions were also asked relating to how students used the tapes, how many copies of the tapes were made, where the tapes were listened to and what feature of the tapes was found to be most useful.

Staff from the Faculties of Law and Education agreed to take part in the project. Two large first year subjects were selected for the research project although, unfortunately, neither subject had very large numbers of students with English as a second language. The grant funding also permitted the purchase of high speed one-to-one cassette copiers one of which was placed in the Law Library on the Gardens Point campus and one in the Kelvin Grove campus library. The Faculty of Law is based at the Gardens Point campus while the Faculty of Education is based at the Kelvin Grove campus. During each semester in 1993 the weekly lecture in each subject was audio recorded and two copies of the lecture along with paper copies of any overhead transparencies used in the lecture were placed in the library on the Limited Access Collection. The Faculty of Education course, Language, Technology and Education was a one semester subject available to Early Childhood, Primary and Secondary Education students while the Faculty of Law subject, Torts, was a full year subject.

\section{The Evaluation Instrument}

The questionnaire was administered to students in the second last week of the semester during tutorial classes.

In Semester 1, a total of 261 students completed the questionnaire while in Semester 2, 274 questionnaires were completed. A disappointing feature of the Semester 1 sample was that only 48 questionnaires were completed by the Law students. In Semester 2, 146 Law students completed the questionnaire. The total number of students who completed the questionnaire was $32 \%$ of the total two semester enrolment in the two subjects. The raw scores indicating how many students used the audio tapes may well be an underestimate of the actual number of users. The percentage responses to the questionnaire may be a fairer estimate of the overall level and pattern of usage if it is assumed that the sample group is a representative sample of the total number of students enrolled in the two subjects. 
The analysis of the questionnaires presented below is based on the number of students who answered the question seeking to obtain information about the level of usage of the tapes. This sample was needed due to the fact that the number of responses to many of the other questions exceeded the number of students that answered this question. I have thus assumed that students answered questions about tape usage without actually themselves having used the tapes.

Of the 269 students who answered the questionnaire in Semester 1, 67 or $23.7 \%$ said they used the tapes, while in Semester 2, 76 or $27.1 \%$ of the 275 students answering the questionnaire said they used the tapes.

\section{How frequently did you use the audiotapes?}

The frequency of use was as follows

\begin{tabular}{lrrrr} 
& \multicolumn{2}{c}{ Semester 1 } & \multicolumn{2}{c}{ Semester 2 } \\
\hline Every week & 15 & $5.3 \%$ & 6 & $2.1 \%$ \\
Between 6-12 times & 4 & $1.4 \%$ & 15 & $5.4 \%$ \\
Between 1 5 times & 48 & $17.0 \%$ & 55 & $19.64 \%$ \\
Never & 202 & $71.6 \%$ & 199 & $71.1 \%$ \\
\hline
\end{tabular}

When these responses were further divided by Faculty it was revealed that the Faculty of Law students used the tapes more heavily than the Faculty of Education students.

The questionnaire sought to obtain information about how the students made use of the tapes.

All the following statistics are an analysis of only those students who completed question 6 indicating that they had used the tapes.

\section{Where did you use the tapes?}

\begin{tabular}{lrrrr} 
& \multicolumn{2}{c}{ Semester 1 } & \multicolumn{2}{c}{ Semester 2 } \\
\hline In the library & 36 & $53 \%$ & 33 & $43.4 \%$ \\
Only at home & 9 & $13.4 \%$ & 24 & $31.6 \%$ \\
Both home and library & 8 & $11.9 \%$ & 18 & $23.7 \%$ \\
Elsewhere & 13 & $19.4 \%$ & 1 & $1.3 \%$ \\
\hline
\end{tabular}

It is significant that quite high percentages used the tapes away from the library which was made possible by the installation of a high speed tape copier in the library. Question 9 asked how many copies of the tapes were made by the students. 
9. How many copies of the tapes did you make?

\begin{tabular}{lrrrr} 
& \multicolumn{2}{c}{ Semester 1 } & \multicolumn{2}{c}{ Semester 2 } \\
\hline 0 & 53 & $79.1 \%$ & 34 & $44.7 \%$ \\
$1-5$ & 12 & $17.9 \%$ & 31 & $40.8 \%$ \\
$6-10$ & 1 & $1.5 \%$ & 6 & $7.9 \%$ \\
$11-14$ & 0 & 0 & 5 & $6.6 \%$ \\
\hline
\end{tabular}

The decision to place a high speed tape duplicator in the library was justified as it certainly enabled a high percentage of the students who used the tapes to make copies and use them away from the campus which reduces pressure on library facilities and provides variety in student learning opportunities.

The results of question 11 indicate that audio tapes of lectures are found to be useful if they are supported by the use of some print materials. In both semesters paper copies of any overhead projector transparencies used in the lectures were stored with the audio tapes.

11. How useful did you find the paper copies of the overhead projector transparencies in understanding the lectures?

\begin{tabular}{lrrrr} 
& \multicolumn{2}{c}{ Semester 1 } & \multicolumn{2}{c}{ Semester 2 } \\
\hline Helped me greatly & 29 & $43.3 \%$ & 33 & $43.4 \%$ \\
Frequently helpful & 13 & $19.4 \%$ & 24 & $31.6 \%$ \\
Occasionally helpful & 13 & $19.4 \%$ & 16 & $21.1 \%$ \\
No help at all & 7 & $10.4 \%$ & 0 & 0 \\
\hline
\end{tabular}

There had been some concern by academic staff that students might elect not to attend lectures if they knew that the lecture was to be audio taped. The results to question 12 show that this did not happen frequently although between 60 and 70 percent of those who used the tapes had missed lectures at some time during the semester and used the tapes to catch up on what they missed.

\section{How frequently did you miss the lectures and only listen to the audiotapes instead?}

\begin{tabular}{lrrrr} 
& \multicolumn{2}{c}{ Semester 1 } & \multicolumn{2}{c}{ Semester 2 } \\
\hline $11-14$ times per semester & 4 & $6 \%$ & 1 & $1.3 \%$ \\
6 - 10 times per semester & 1 & $1.5 \%$ & 5 & $6.6 \%$ \\
1 - 5 times per semester & 39 & $58.2 \%$ & 53 & $69.7 \%$ \\
Never & 22 & $32.8 \%$ & 17 & $22.4 \%$ \\
\hline
\end{tabular}

Question 13 asked specifically if the tapes were used to catch up on material if the student had missed a lecture. In Semester 1, 76.1\% of those who used the tapes said yes, while in Semester 2, 86.8\% confirmed this use 
of the tapes. On the other hand the students made less extensive use of the tapes to prepare for examinations as the results to question 14 revealed. In Semester $1,37.3 \%$ said they used the tapes to prepare for examinations while in Semester 2, 38.2\% used the tapes for this purpose. Some use was also made to prepare for tutorials as the results to question 18 indicate.

\section{How frequently did you listen to the tapes to prepare for tutorials?}

\begin{tabular}{lrrrr} 
& \multicolumn{2}{c}{ Semester 1 } & \multicolumn{2}{c}{ Semester 2 } \\
\hline Every week & 12 & $17.9 \%$ & 2 & $2.6 \%$ \\
6 - 12 times per semester & 0 & $0 \%$ & 3 & $3.9 \%$ \\
$1-5$ times per semester & 15 & $22.4 \%$ & 18 & $23.7 \%$ \\
Never & 38 & $56.7 \%$ & 53 & $69.7 \%$ \\
\hline
\end{tabular}

Questions were asked to see what features of the tapes the students found most useful. Question 15 asked if the tapes helped the students to understand the subject material.

\begin{tabular}{lrrrr} 
& \multicolumn{2}{c}{ Semester 1 } & \multicolumn{2}{c}{ Semester 2 } \\
\hline Helped a great deal & 20 & $29.9 \%$ & 39 & $51.3 \%$ \\
Some use & 35 & $52.2 \%$ & 33 & $43.4 \%$ \\
Little use & 6 & $9 \%$ & 3 & $3.9 \%$ \\
No use & 3 & $4.5 \%$ & 1 & $1.3 \%$ \\
\hline
\end{tabular}

Question 19 probed this aspect even further.

19. Indicate the feature of having the audiotapes available that you found most helpful. (Tick one box only)

\begin{tabular}{lrrrr} 
& \multicolumn{2}{c}{ Semester 1 } & \multicolumn{2}{c}{ Semester 2 } \\
\hline To review difficult/ complex material & 19 & $28.4 \%$ & 17 & $22.4 \%$ \\
To catch up on material covered in lectures & 32 & $47.8 \%$ & 43 & $56.6 \%$ \\
I did not attend & 2 & $3 \%$ & 2 & $2.6 \%$ \\
To revise content prior to examinations & 8 & $11.9 \%$ & 12 & $15.8 \%$ \\
To have the freedom to listen to the lectures & & & & \\
in my own time & & & & \\
\hline
\end{tabular}

It had been thought that the existence of the tapes may have reduced the note taking by students during the lecture. The results to question 16 revealed that the use of the tapes did not greatly reduce note taking in lectures. In Semester 1, 83.6\% said the existence of the tapes made no difference in their note taking while in Semester 2, 89.5\% also checked this response.

The response to question 17 revealed some surprises about the way in which the students listened to the tapes. While it would be expected that 
users would stop the tape frequently and make notes while listening to the tapes a surprisingly high percentage claimed that they listened without stopping. This could indicate poor ability to use this media effectively in learning or perhaps the lectures were not worth taking notes from!

\section{When listening to the audiotapes did you most often}

\begin{tabular}{lrrrr} 
& \multicolumn{2}{c}{ Semester 1 } & \multicolumn{2}{c}{ Semester 2 } \\
\hline Listen without stopping? & 12 & $17.9 \%$ & 16 & $21.1 \%$ \\
Stop frequently to take notes? & 34 & $50.7 \%$ & 43 & $56.6 \%$ \\
Listen to sections only to review difficult & 11 & $16.4 \%$ & 6 & $7.9 \%$ \\
content? & 5 & $7.5 \%$ & 9 & $11.8 \%$
\end{tabular}

Listen right through and replay to take

notes?

One of the consequences of large classes for academic staff is the number of students that seek them out after the lecture seeking clarification of issues. It had been thought that the audio tapes may reduce the need for students to ask the lecturer questions. Question 20 sought to obtain information on this aspect.

\section{How often did the use of the audiotapes reduce the need for you to ask the lecturer/tutor a question?}

\begin{tabular}{lrrrr} 
& \multicolumn{2}{c}{ Semester 1 } & \multicolumn{2}{c}{ Semester 2 } \\
\hline At least once every week & 4 & $6 \%$ & 4 & $5.3 \%$ \\
7 - 12 times during Semester & 2 & $3 \%$ & 6 & $7.9 \%$ \\
1 - 6 times during Semester & 16 & $23.9 \%$ & 28 & $36.8 \%$ \\
Never & 39 & $58.2 \%$ & 37 & $48.7 \%$ \\
\hline
\end{tabular}

These results indicate that the use of the audiotapes does reduce the need for students to seek questions from the staff.

\section{Conclusions}

A final series of questions was asked of the Teacher Education students regarding the use of the video recording on these lectures. Quite small numbers of students used the video recordings and of those who used both the video recordings and the audio recordings the overwhelming response was that the video recordings were more helpful in understanding the subject.

In summary the assumption that students would use the audio tapes to catch up on material missed when they failed to attend a lecture was confirmed and that the ability to make copies of the tapes was used frequently enough to justify the decision to install the high speed tape duplicators in the libraries. 
As expected the paper copies of the overhead transparencies are a valued aid to the use of the tapes although the quite high percentage that used the tapes without taking any notes raises questions about how skilled some students are in using audiotapes for learning. The fact that around $50 \%$ of those who used the tapes used them away from the library would indicate that the audio recording of lectures on a more widespread basis would lead to some reduction in pressure on library facilities providing tape copying equipment was readily available.

Author: Geoffrey Roberts is the Director of Audiovisual Services Department at the Queensland University of Technology, Locked Bag No. 2, Red Hill, Qld 4059. QUT has 24,000 students located at four campuses in Brisbane. The University has eight Faculties: Business, Arts, Law, Health, Science, Information Technology, Built Environment and Engineering and Education.

Please cite as: Roberts, G. (1994). An evaluation of the use made by students of the audio recording of lectures. Australian Journal of Educational Technology, 10(2), 96-102.

http://www.ascilite.org.au/ajet/ajet10/ roberts.html 